\title{
Progress towards Universal Health Coverage: Is Cameroon Investing Enough in Primary Care?
}

\author{
Chenjoh Joseph Nde ${ }^{1, *}$, Alice Raymond ${ }^{2}$, Ndong Ignatius Cheng ${ }^{3}$, Guy Roger Etoundi ${ }^{4}$, Yauba Saidu $^{2}$, \\ Johannes Tabi Atemnkeng ${ }^{5}$, Wilfred Fon Mbacham ${ }^{6}$
}

\author{
${ }^{1}$ Department of Health Economics, Policy and Management, Faculty of Business and Management, \\ Catholic University of Cameroon, Cameroon \\ ${ }^{2}$ Clinton Health Access Initiative, Senegal \\ ${ }^{3}$ Noguchi Memorial Institute for Medical Research, College of Health Sciences, University of Ghana, Ghana \\ ${ }^{4}$ Technical Secretariat for the Health Sector Strategy, Ministry of Public Health, Cameroon \\ ${ }^{5}$ Department of Economics and Management, Faculty of Social and Management Sciences, University of Buea, Cameroon \\ ${ }^{6}$ Unit for Life Sciences and Biological Organisms, Faculty of science, University of Yaounde I, Cameroon
}

Copyright $\bigcirc 2019$ by authors, all rights reserved. Authors agree that this article remains permanently open access under the terms of the Creative Commons Attribution License 4.0 International License

\begin{abstract}
Cameroon faces significant income and health inequalities, due to the health sector's reliance on out-of-pocket spending for $70 \%$ of healthcare financing. To solve this problem, the government in 2015 began reflections for the putting in place of a universal health coverage (UHC) scheme. However, a number of planning, budgeting and resource management processes must be strengthened to facilitate this reform. This paper aims at reviewing the structure of resource allocation within the ministry of health to assess if it reflects the government's desire to enhance service availability and readiness for the impending UHC. Data was derived from finance laws (chapter 40) of 2014 to 2018 . The data was analyzed using Microsoft Excel. The results reveal a high centralization of the budget in favor of the central administration to the detriment of the operational level. Allocations to the regional and district levels are insensitive to the size and needs of the population of the regions and districts. As a consequence, there are great disparities between the regions and between urban and rural areas, leading to inequity in service delivery. In order to increase the quantity and quality of primary care in an effort to reach UHC, we recommend that more resources be directed to the operational level while district managers are capacitated to effectively and efficiently use these funds.
\end{abstract}

Keywords Universal Health Coverage, Budget, Review, Allocation, Cameroon

\section{Introduction}

Cameroon is located in West Africa with a population of about 21 million people and a population growth rate of 2.6\%.[1] The GDP of Cameroon for 2017 is estimated at 34.8 billion USD giving a GDP per capita of 1,446 USD.[2] With a poverty rate of about $37.5 \%$, the average Cameroonian lives on less than 2 USD per day.[3] Key health indicators for the country reveal that the HIV prevalence rate stands at 3.4\%[4] while maternal mortality is estimated at 782 for every 100,000 live births.[5] Cameroon did not achieve the maternal and child-related Millennium Development Goals (MDGs), and ranks 145 out of 179 countries on the mother's index, lagging behind its peers like Mozambique, Uganda, and Zimbabwe.[6]

Cameroon currently has one of the lowest levels of publicly-funded healthcare in the sub-Saharan region (9.20 USD per capita). The health budget decreased by $24 \%$ between 2016 and 2018, reflecting a general trend of economic decline and resource shortages.[7] Cameroon faces significant income and health inequalities, due in part to the health sector's reliance on out-of-pocket spending which accounts for $70 \%$ of total health expenditures.[1] A recent household study in Cameroon's three northern regions (Adamawa, Far North and North) revealed that 64 percent of patients who did not seek care at a health center or from a health professional cited cost as the most important reason.[8] Also, health expenditures increase the poverty rate by almost 2 percentage points, and exacerbate the depth of poverty by almost 12 percentage points in the country.[9] The Government by 2015, started seeking to remedy this inequity by implementing a universal health coverage (UHC) scheme, but a number of planning, budgeting, and resource management processes must be strengthened to facilitate this reform. Moving towards UHC implies addressing two 
major components of the health system: 1) Strengthening service delivery to ensure availability of quality health care throughout the national territory and 2) Restructuring the financing of the demand for health.

In consultation with health experts, technical and financial partners and civil society, Cameroon has opted to limit the implementation of the first phase of the UHC to the essential package of activities offered by district level health facilities. This implies that Integrated Health Centers (IHCs), Medicalized Health centers (MHCs) and District Hospitals (DHs) will be directly concerned with providing the services contained in the essential benefit package. Improving service delivery entails ensuring service availability and readiness by upgrading the technical platform (human resources for health, infrastructure and equipment) of health facilities at the regional and district levels, hence the need for more resources to be invested at these levels. In parallel, regional and district staffs will have to be capacitated to ensure an efficient management of these resources.

In the midst of decreasing allocations to the ministry of health $(\mathrm{MoH})$ by the central government, this paper intends to review the structure of resource allocation within the ministry, to assess whether the current budget allocation structure reflects the government's desire to enhance primary care service availability and readiness (increase the quality and quantity of care) thereby preparing the health system for the implementation of the impending UHC.

\section{Methods}

Data was extracted from chapter 40 of the finance law (2014, 2015, 2016, 2017 and 2018) which concerns allocations to the $\mathrm{MoH}$ for the year 2014 to 2018. The data was cleaned and ordered to facilitate analysis.

Using the budget codes (Article and Paragraph numbers), trends in spending between the central and district (operational) levels were categorized in terms of budget holder, regional earmarking, facility earmarking, spending types and programmatic funding. Using Microsoft excel, these were filtered and sorted using either the paragraph or article numbers. Paragraph numbers were composed of 4 digits (e.g. 6101 or 2319) while article numbers were composed of 6 digits (e.g. 33 0002 ). There were two types of paragraph numbers; those starting with the number 2 which denote investments and those starting with the number 6 , denoting the operational budget.

On the basis of the article numbers, numbers in the $3^{\text {rd }}$ and $4^{\text {th }}$ positions $(33 \mathrm{xx} 02)$ were used to identify allocations to the central and regional levels as follows: 00 - Central level, 10 - Adamawa, 11 - Centre, 12 - Est, 13
- Extreme North, 14 - Littoral, 15 - North, 16 - North West, 17 - West, 18 - South, 19 - South West.

The type of structure or health facility was identified using the article number, with numbers in the $1^{\text {st }}$ and $2^{\text {nd }}$ positions (xx 0002 ) as identifiers of the type of structure within the region as follows: 44 - Regional Delegation (RD), 45 - district health services (DHS), 52 - General and Central Hospital, 53 - Regional Hospital (RH), 54 District Hospital (DH), 55 - Medicalized Health Center (MHC), 56 - Integrated Health Center (IHC), and 57 Frontier Health Post (FHP). Average allocations for each type of structure within each region were calculated by dividing the total amount for all the facilities by the number of facilities within the region. Total allocation for both the decentralized and central levels was calculated by adding both operating and investment budgets for all structures.

Central level allocations were divided into the following categories: salaries, drugs and medical equipment, and other expenses for hospitals (Construction, expansion, rehabilitation of buildings for hospitals and other health centres, acquisitions, renovations, major maintenance of hospital equipment and facilities, Capital transfers to Autonomous Public Establishments (APEs) and other public bodies). In order to estimate the share of budget that will be invested at the central level, these categories were subtracted from the total central level allocation. This enabled us to distinguish direct central level spending from central level allocation spent on direct service provision at the regional level or operational level. Operating budget allocation and total allocation at facility level (RH, DH, MHC and IHC) per capita was calculated by dividing the total allocation for the region by the population of the region.

However, there are limits to the extent to which the data can be analyzed based on the budget code. For example, Investment budget versus operational budget were easily disaggregated based on the paragraph codes however it is not possible to disaggregate further. It should be noted that because we are looking at budget data, it is not necessarily representative of total health spending for Cameroon.

\section{Results}

\subsection{Budget Allocation to the MOH}

In April 2001, heads of state of African Union countries met and pledged to set a target of allocating at least $15 \%$ of their annual budget to health in order to improve the health sector. [10] In line with this pledge, for the period 2014 to 2017, the budget allocation to the $\mathrm{MoH}$ in Cameroon is presented on table 1 below: 
Table 1. Budget allocation to the MoH from $2014-2018$ (values in millions of USD)

\begin{tabular}{|l|c|c|c|c|c|}
\hline Budget component & 2014 & 2015 & 2016 & 2017 & 2018 \\
\hline MoH Budget & 331.7 & 414.1 & 472.3 & 416.4 & 356.5 \\
\hline Annual growth in MoH budget (\%) & 2.39 & 24.84 & 14.05 & -11.84 & -14.39 \\
\hline Total state budget (millions of USD) & 6,624 & $7,493.2$ & $8,469.4$ & $8,747.6$ & 9,027 \\
\hline Part of total state budget allocated to MoH (\%) & 5 & 5.5 & 5.6 & 4.8 & 3.9 \\
\hline
\end{tabular}

Source: Finance law 2014-2018

Table 1 shows the budget allocation to the $\mathrm{MoH}$ in relation to the total state budget from 2014 to 2018. The growth rate of the budget was positive between 2014 and 2016, however, from 2017 to 2018 the budget growth rate has been negative $(-11.84 \%$ and $-14.39 \%$ respectively). For the five-year period the total $\mathrm{MoH}$ budget growth rate is $15.05 \%$. From 2014 to 2018 the average budget allocation in relation to the total state budget is estimated at $4.95 \%$. This is insufficient when compared to the prescribed target health expenditure of $15 \%$ that the country has committed itself to through the Abuja declaration, so as to achieve the goal of access to health care for all. [11]

\subsection{Investment and Operational Budget Allocations}

The budget is composed of two major components that are investment and operations. The budget distribution between these two components for each year is illustrated on figure 1 below:

Figure 1 shows that between 2014 and 2017 there was a steady rise in the investment budget. However, from 2017 to 2018 , the trend reversed drastically with the investment budget registering a sharp fall to $15.1 \%$ while the operational budget more than doubled the investment budget and stood at $84.9 \%$ of the total $\mathrm{MoH}$ budget.

\subsection{Budget Distribution between the Central and Operational Level}

The budget allocation between the central level and the regions (operational level) is shown on figure 2 below.

Figure 2 illustrates that for the period 2014 to 2018 averagely $89 \%$ of the $\mathrm{MoH}$ budget was allocated to the central level while only about $11 \%$ of the budget was allocated directly to the operational level. A deeper look into the central level allocation reveals that averagely about $29 \%$ was dedicated to salaries, $1.8 \%$ for drugs and medical supplies, $40.2 \%$ represented investments for the operational level by the central level and about $18 \%$ represented direct central level expenditure. Total allocation to the central level is estimated at an average of $89 \%$. For investments at the operational level to be done from the central level $(40.2 \%)$ the expenditure circuit becomes stretched increasing the probability for more leakages in the system. This most likely explains the low level of budget execution within the $\mathrm{MoH}$, which is estimated at $86.6 \%$ from 2015 to 2017.

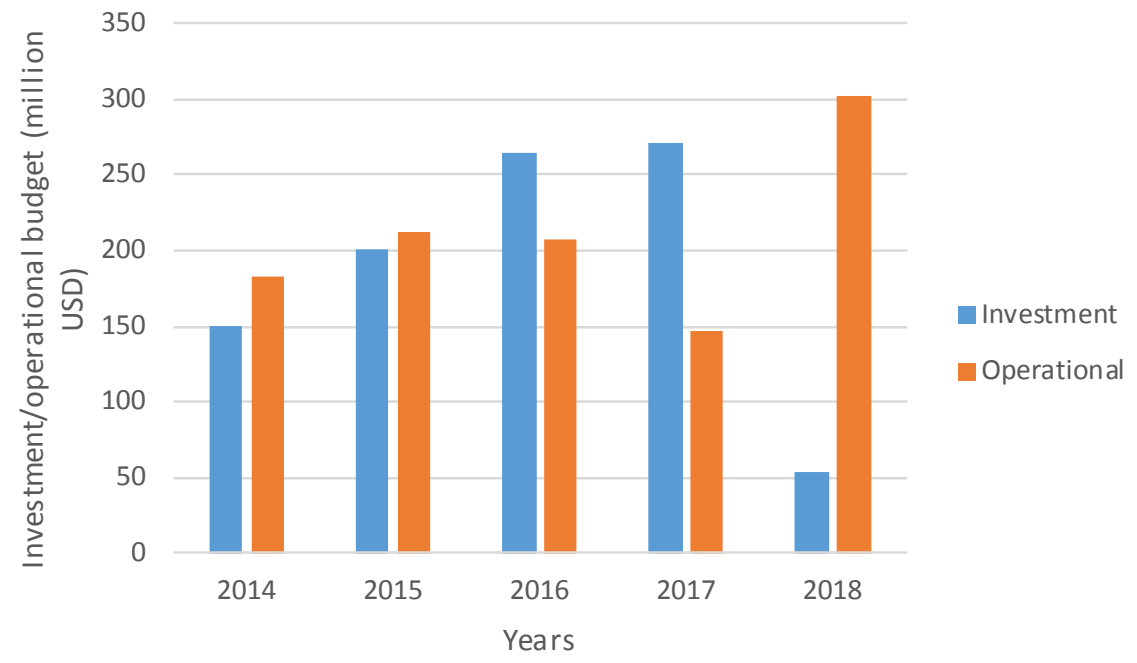

Figure 1. Functioning and investment budget allocation from 2014 to 2017 


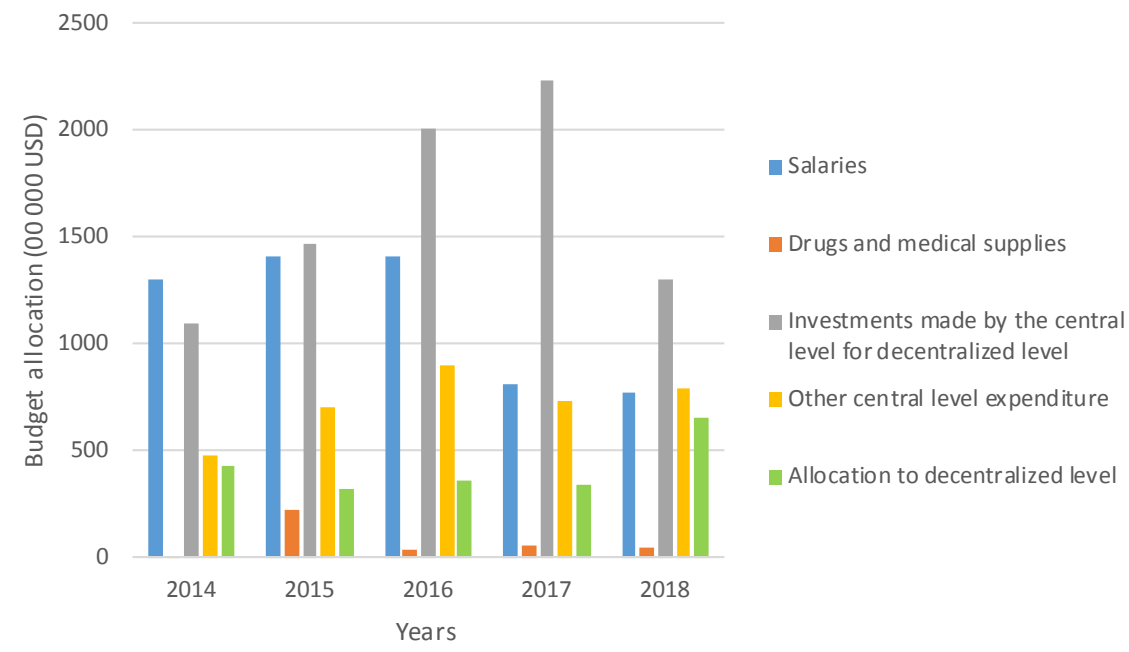

Figure 2. Budget allocation between the Central and Decentralized structures

\subsection{Regional Level Allocation}

Trends in the budget allocation to the regions are represented on the figure 3 below:

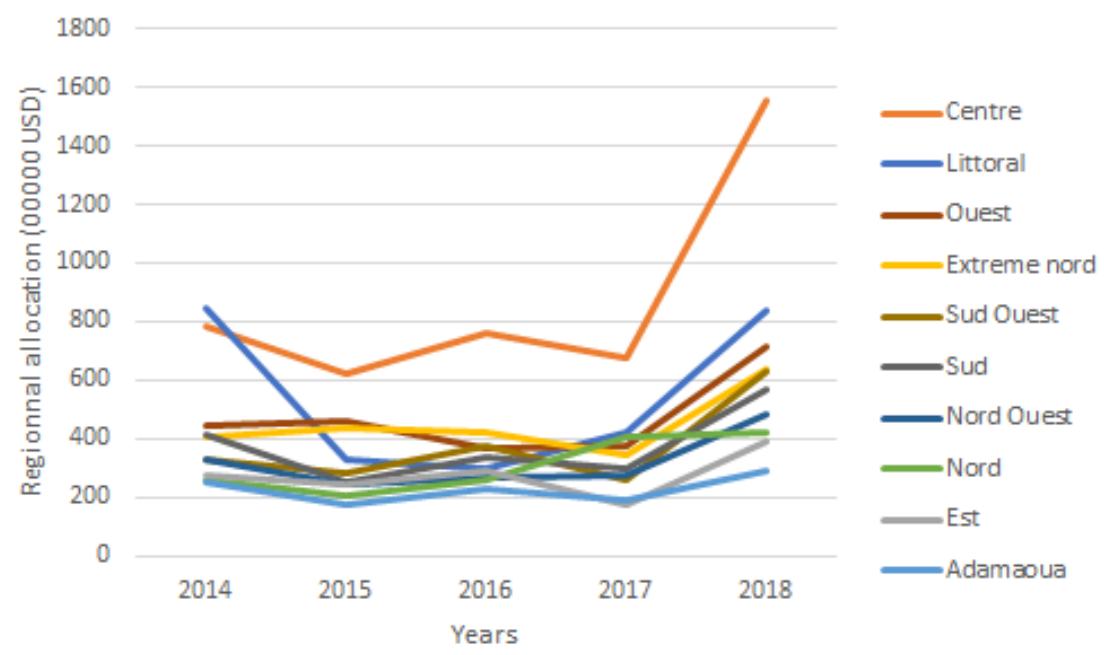

Figure 3. Trends in the health budget allocation to the regions from 2014 to 2018

Figure 3 reveals that the total budget allocated directly to the 10 regions fell from $13 \%$ in 2014 to $8 \%$ in 2015 and remained fairly stable until 2017 . However, although the budget allocated to the $\mathrm{MoH}$ fell over the period 2017 and 2018 , total allocation to the regions increased sharply by about $90.9 \%$ i.e. increasing from 34 million USD in 2017 to 64 million USD in 2018. It is widely expected that this allocation to the operational level will lead to an improvement in the quantity and quality of services offered by facilities at the operational level.

\subsection{Per Capita Regional Health Facility Allocations}

The per capita budget allocation to the regions is represented on figure 4 below.
Figure 4 demonstrates that regional per capita facility allocations for the South, South West and East regions estimated at USD 1.80, 1.42 and 1.2 respectively, are the highest compared to those of the other regions. Meanwhile, the lowest regional per capita facility allocations are recorded for the North, Far North and Adamawa regions (Grand North) which stand at USD $0.48,0.50$ and 0.50 respectively.

\subsection{Average Allocation to Facilities at the District Level}

Average budget allocation to health facilities at the level of the district i.e. DHS, DH, MHC and IHC is shown on the table below. 


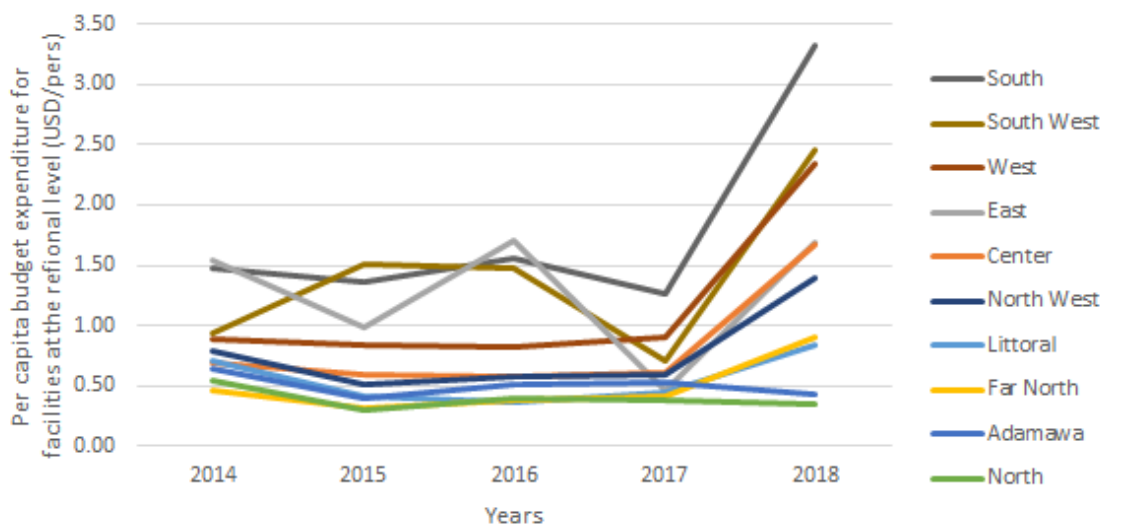

Figure 4. Regional health facility per capita budget allocation for IHC, MHC, DH and RH

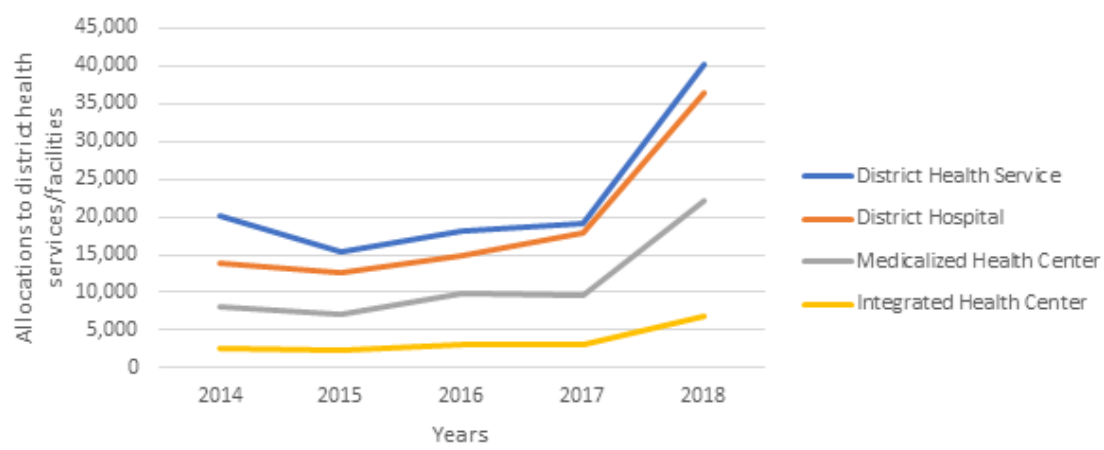

Figure 5. Allocations to district health services and facilities from 2014 to 2018

Figure 5 indicates that, allocations to the various structures dropped slightly from 2014 to 2015 , then from 2015 to 2017 they remained fairly stable for all structures. However, from 2017 to 2018 , allocations to the district health structures more than doubled for all health structures concerned. The budget for district health services, district hospitals, medicalized health centers and integrated health centers increased by $124 \%, 140 \%, 127 \%$ and $184 \%$ respectively. A look at a typical detailed budget allocation of a health facility is shown on table 2 below:

Table 2. Example of the budget allocation structure of an Integrated Health Center the Case of Mora IHC (Extreme North region) for 2016 (Values in USD)

\begin{tabular}{|l|c|}
\hline \multicolumn{1}{|c|}{ Description } & $\begin{array}{c}\text { Amount } \\
\text { allocated }\end{array}$ \\
\hline Purchase of supplies and office maintenance & 1,500 \\
\hline $\begin{array}{l}\text { Other current services supplies (excluding office } \\
\text { and technical supplies) }\end{array}$ & 1,500 \\
\hline Total & 3,000 \\
\hline
\end{tabular}

Source: MoH Budget 2016

From the table above, we realize that the budget allocated to health facilities are clearly earmarked, dictating to health facility managers what they are supposed to spend the budget allocated to their facility and how much to spend on each element of the budget.

\section{Discussion}

The aim of this paper was to review the budget allocation of the MoH for a five-year period (2014 to 2018) in order to assess if it clearly reflects government's desire to achieve UHC by enhancing primary care service availability and readiness through the allocation of more resources to the operational level.

Cameroon's progress in allocating at least $15 \%$ of its budget to health over the five year period remains largely insufficient (average allocation in relation to the state budget at $4.95 \%$ ) when compared to twenty-seven African countries that have so far increased the proportion of their total government expenditure for health since 2001. Cameroon is classified alongside the Democratic republic of Congo, Chad, Kenya, and Gambia whose progress is considered insufficient and lagging behind peers such as Tanzania that have has reached the target.[10] The inability of the country to make significant progress towards the $15 \%$ allocation target is probably due to the gap between policy and practice given that in the country's growth and employment strategy paper (GESP) 
health is clearly highlighted as a priority area which contributes significantly to the growth of the economy. In addition, poor health indicators which directly create the need for more investments in the health sector seem not to be attracting more investments into the health sector. For example, it is estimated that each year, more than 7,000 women die due to pregnancy related causes, as well as 58,000 children under 5 years of age. [12, 13] However, some experts argue that the target of allocating $15 \%$ of the total budget to health out rightly undermines the autonomy of the Ministry of Finance to make sectoral budget allocation decisions. [14] They claim that by calling for an increased share of government expenditure to the health sector, less will be spent on other social services that also contribute to the health of the population. [15] In spite of the decreasing allocations vis-à-vis an ever-increasing list of health needs, the average budget execution rate from 2015 to 2017 is estimated at $86.6 \%$. [16] This clearly highlights the public financial management challenges the health sector faces which contribute to the sector's inability to fully absorb and consume its budget. This recurrent phenomenon nullifies advocacy efforts aimed at securing more resources for the health sector. Achieving better performing health systems with a wider more equitable coverage of health services require a twofold approach of first ensuring that existing resources are utilized more effectively and efficiently and secondly, generating additional public and private resources needed to bolster economic growth. [17]

The steady rise in the investment budget of the $\mathrm{MoH}$ starting from 2014 and reaching a peak in 2017, illustrates the government's commitment and desire for systematic improvements in the health system - through the construction of health facilities and purchasing of hospital equipment. Despite the sustained investment, with regards to the availability of health infrastructure, Cameroon is classified $29^{\text {th }}$ out of 35 sub-Saharan African peers with an estimated coverage of 0.63 health facility per 100,000 people. Cameroon is lagging behind poorer peers such as Liberia, Sierra Leone and the Central African Republic. [18] However, the increase in investments at the detriment of the operational budget raises concerns given that, most key health indicators have either remained unchanged or deteriorated such as one woman dying every two hours from complications related to pregnancy or childbirth over the past decade. [13] However there are arguments pointing to the fact that rather than build more health facilities, the government should increase the operational budgets of existing health facilities in order to improve the quality of care. This owes to the fact that the provision of quality health services remains a major challenge, with significant differences between the regions and between rural and urban areas of the country. [19] For example, in the Adamawa region, only $33 \%$ of facilities have clean water, compared to $94 \%$ in the North West and $95 \%$ in the South West. [20]
Since 1996, the government has been engaged in the process of decentralization with ten regional delegations of public health that coordinate a total of 189 health districts. The general argument for decentralizing health care is its potential for improving service quality and coverage [21] which directly reflects the goals of UHC. However, the decentralization process in the health sector has not been accompanied by a significant reallocation of resources from the central level towards the periphery or operational level (the regions and districts). From 2014 to 2018 , about $89 \%$ of the budget of the $\mathrm{MoH}$ was allocated to the central level (salaries included) and just about 11\% directly to the regional level. Operational level structures continue to depend on the central level for budget execution which is contrary to the tenets of decentralization. It is recommended that in order for the health system to be better prepared for UHC, more resources should be allocated to the benefit of the operational level.

The general logic guiding budget allocations in the $\mathrm{MoH}$ is that of institutional equality. What this means is that all health institutions that are ranked at the same level of the health pyramid receive the same budget allocation irrespective of the population to be covered, general morbidity, social and economic characteristics of the area. This is because current budget allocation systems do not support the linking of vital health information to resource use and allocation. Consequently, regions with a higher number of health facilities will always have a higher budget than those with fewer health facilities. For example, the Center region with the highest number of health facilities always has a higher budget compared to the North and the Far North regions with far less health facilities. This aggravates the health disparity between the regions because while for the Center region the ratio of the population to a primary health facility is 4902 , in the North, Far North and Adamawa regions it is 8840, 13030 and 7604 respectively. [1] The per capita regional health facility allocations for regions such as the East with a smaller population which is estimated at $1.28 \mathrm{USD}$, is three times higher than that of the North region which is estimated at 0.39 USD. Whereas, the North, Far North and Adamawa regions which have a higher population, are faced with serious health challenges with under-five mortality four times higher in the North than in Center (173 deaths per 1,000 live births as against 42), while acute malnutrition is 11 times higher in the Far North than in the West region. [16] Given this situation, there is a need for Cameroon to develop a more efficient system of budgetary allocation to the regions. Allocations based on the population (i.e. total population or target population), poverty index or health status could be considered.

In Cameroon, the establishment of the UHC depends primarily on healthcare providers at the primary level such as the DH, MHC and IHC. In the 2018 budget, Primary health care structures were clearly prioritized in the 
budget of the MoH as their allocations almost doubled. Though this move is laudable and aimed at improving health outcomes at the primary healthcare level, the budget structure which is composed of earmarked budget lines for health facilities as shown on table 2 above, makes the attainment of such an objective very challenging. Earmarked budget lines, limit autonomy and flexibility for health facility managers. Experience from other countries shows that global budgets are more effective and can improve the quality of care and the performance of health facilities. [22] Therefore, there is a need for the structure of budget allocations to health facilities to move from earmarked budget lines to global budgets. In addition, increasing allocations to primary healthcare facilities while ignoring the capacity constraints at the district levels could be counterproductive and lead to the mismanagement of these funds. There is a need for health facility managers to be capacitated so as to ensure a better management of these resources. [18]

\section{Conclusions}

Though reflections for the implementation of the UHC in Cameroon started in 2016, allocations to the operational level did not reflect the desire of empowering health facilities at the operational level to improve the quantity and quality of services. It has taken two years since 2016 for the government to begin allocating more resources to the operational level with an allocation of about 34 million USD in the 2018 budget compared to about 14 million USD for 2017. However, allocating more resources without increasing other inputs such as human resources for health and capacitating health facility managers for an effective and efficient utilization of the funds, may not lead to the much-desired effect of improving service availability and readiness in the face of the impending UHC.

\section{Declarations}

The datasets used and/or analyzed during the current study are available from the corresponding author on reasonable request.

\section{Competing Interests}

The authors declare that they have no competing interests.

\section{Funding}

MARCAD

\section{Authors' Contribution}

CJN - Analyzed the data and developed the methods

AR - Analyzed part of the data

NIC - Developed the abstract

GRE - Contributed in writing parts of the discussion

YS - Prepared the introduction, conclusion and reviewed the write up

JTA - Supervised, gave suggestions and reviewed the article

WFM - Supervised, made suggestions and reviewed the article

\section{Acknowledgements}

We thank our colleagues from the Ministry of Health of Cameroon and members of the Health Financing Strategy and Universal Health Coverage Sub-Working Group of Technical and Financial Partners who provided insight and expertise that greatly assistes the research, although they may not agree with all of the interpretations/conclusions of this paper.

This article was supported in part through WFM by the DELTAS Africa Initiative. The DELTAS Initiative is an independent funding scheme of the African Academy of Sciences (AAS)'s Alliance for Accelerating Excellence in Science in Africa (AESA) and supported by the New Partnership for Africa's Development Planning and Coordination Agency (NEPAD Agency) with funding from the WELLCOME Trust [10774/A/15/Z of March 30, 2016] and the UK government. The views expressed in this publication are those of the author(s) and not necessarily those of AAS, NEPAD Agency, Wellcome Trust or the UK government

\section{REFERENCES}

[1] Ministry of Public Health. Cameroon Health Sector Strategy $2016-2027$

[2] World Bank Data [Internet]. 2018. [Cited 2018 September 6] Available from: https://data.worldbank.org/indicator/NY.G DP.PCAP.CD? locations $=\mathrm{CM}$

[3] World Bank Data [Internet]. 2018. [Cited 2018 September 16]. Available from: https://data.worldbank.org/country/ca meroon

[4] Ministry of Public Health, CAMPHIA results. 2018

[5] National Institute of Statistics. Multiple Indicator Health and demographic Survey (EDS). 2011

[6] World Bank. 2018. Cameroon, Public Expenditure Review. Aligning public expenditures with the goals of Vision 2035.

[7] Republic of Cameroon, Finance law 2016, 2017, 2018 
[8] IFORD. 2015

[9] ADePT analysis with 2012 NHA data, Diagnostic chapter of Health Financing Strategy.

[10] WHO. The Abuja declaration: Ten years on. 2011

[11] National Institute of Statistics. Second survey on the monitoring of public expenditures and the level of recipients' satisfaction in the health sector in Cameroon (PETS2). 2010.

[12] UNFPA. 2014. Multisectoral program to reduce maternal \& child mortality. [Cited 2018 November 5] Available at https://cameroon.unfpa.org/fr/news/government-cameroonlaunches-multisectoral-program-reduce maternal-child-mortality

[13] Cameroon. [Internet] WHO statistical profile. [Cited 2018 October 11]. Available from:http://www.who.int/gho/count ries/cmr.pdf?ua $=1$

[14] Njora, G. African finance ministers dismiss development declarations. [Cited 2018 November 12] FAHAMU. 2010 Available from: http://pambazuka.org/en/category/commen t/63894 [25 May 2010].

[15] World Bank. Cameroon: country status report on health. 2013

[16] Minister's presentation to parliament during the budgetary sessions of 2015 to 2017

[17] Durairaj V, Jehu-Appiah C, Dukhan Y, Bilal, N, Lannes L. and Sergent, F. Transforming People's Lives in Africa through financial Inclusion in Health. In Soucat, A., and Mthuli, N. One Billion People, One Billion Opportunities. [Internet]. Tunis. African Development Bank. Chapter 23.

Phcpi. Health center density (per 100,000 population).

Available from:https://improvingphc.org/indicator/health-c enter-density-100000-population\#?loc=accessed on

$2 / 7 / 2019$

[18] IFORD, World Bank, Ministry of Public Health. PBF Impact Assessment Survey. 2015.

[19] World Bank. Cameroon, Public Expenditure Review. Health. 2017

[20] Litvack J. Ahmad J. Bird R. Rethinking Decentralization in Developing Countries. [Internet]. The World Bank. Sector study series. 1998. [Cited 2018 December 10] Available from: http:/www1.worldbank.org/publicsector/decentraliza tion/Rethinking\%20Decentralization.pdf

[21] Langenbrunner JC. Cashin C. O'Dougherty S. Designing and Implementing Health Care Provider Payment Systems: How-To Manuals. [Internet]. 2009. Washington, DC: World Bank. [Cited 2018 December 6]. Available from: https://openknowledge.worldbank.org/handle/10986/13806 License: CC BY 3.0 IGO. 